\title{
Minimally-invasive liver resection for liver tumors in children: a snapshot of the current landscape
}

\author{
Miriam Cortes-Cerisuelo', Michael Berger ${ }^{2}$ \\ 'Liver Transplantation, Institute of Liver Studies, Liver Transplant Surgery, King's College Hospital, National Health Service \\ Foundation Trust, London SE5 9RS, UK. \\ ${ }^{2}$ Department of Pediatric Surgery, Research Laboratories, Dr. von Hauner Children's Hospital, Ludwig-Maximilians- \\ University, Munich 80337, Germany.
}

\begin{abstract}
Correspondence to: Dr. Michael Berger, Department of Pediatric Surgery, Dr. von Hauner Children's Hospital, LudwigMaximilians-University, Lindwurmstrasse 4, Munich 80337, Germany. E-mail: michael.fabian.berger@gmail.com
\end{abstract}

How to cite this article: Cortes-Cerisuelo M, Berger M. Minimally-invasive liver resection for liver tumors in children: a snapshot of the current landscape. Mini-invasive Surg 2019;3:1. http://dx.doi.org/10.20517/2574-1225.2018.60

Received: 29 Aug 2018 First Decision: 8 Nov 2018 Revised: 28 Nov 2018 Accepted: 11 Dec 2018 Published: 8 Jan 2019

Science Editor: Fernando Andrés Alvarez Copy Editor: Cui Yu Production Editor: Huan-Liang Wu

\begin{abstract}
Minimally-invasive liver resection (MILR) is a promising approach and has become a standard therapy option for a variety of indications, including liver tumors, in adults. Although minimally-invasive techniques are common practices in children, the usage and literature regarding MILR in children is scarce. In this article, we give an update on the current literature, share some of our own experience and give a future outlook of the potential benefits and shortcomings regarding MILR in children.
\end{abstract}

Keywords: Minimally-invasive liver resection, pediatric cancer, hepatoblastoma, laparoscopy, liver tumor

\section{INTRODUCTION}

Minimally-invasive liver resection (MILR) has been successfully integrated as a valuable surgical tool in adult patients both for cancer resections as well as donor hepatectomies for liver transplantation ${ }^{[1-3]}$. Although minimally-invasive surgical techniques are an essential component in the treatment of pediatric patients with hepatobiliary disease, literature on MILR hepatic tumors in children is scarce. This understanding is explained at least partially by the immense rarity of these tumors in the pediatric age group. In order to better standardize the invasive and complex treatment of hepatic malignancies in children and to obtain more reliable research data regarding their treatment, corresponding study groups from different parts of the world have put in place a global interdisciplinary initiative called The Children's Hepatic Tumors

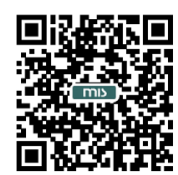


International Collaboration (CHIC) ${ }^{[4]}$. One of the tasks in this collaboration is the standardization of the surgical resection involved, by whatever means. In this article, we focus on reviewing the existing literature on MILR in children and try to give an outlook of the possibilities and limitations of applying MILR in children with cancer and how it could fit into current, standardized treatment strategies.

\section{MILR IN ADULTS}

MILR is now considered an established treatment option in adult liver tumor surgery with a curative intent of both benign and malignant disease ${ }^{[1-3]}$. This advancement has been the result of increased surgical experience, high-quality imaging laparoscopes with better visualization of the operative field and the availability of specialized laparoscopic instruments for transecting the liver parenchyma ${ }^{[3,5,6]}$. In large centers, outcomes and complication rates are similar to those of open resection, notwithstanding the known benefits of a minimally-invasive surgical approach ${ }^{[2,7]}$. Currently, there is an international multicenter randomized controlled trial in Europe (ORANGE PLUS-II) comparing open $v s$. laparoscopic right or left hemihepatectomies for malignancies with the main outcome being time to functional recovery (https://clinicaltrials.gov/ct2/show/NCT01441856).

The knowledge acquired from minimally-invasive liver surgery (MILS) for liver tumors in adults has opened the horizon for a variety of additional indications for MILS in the adult population. For example, in addition to tumor resections, MILR has now gained acceptance as a means for resections carried out for live donor liver transplant, especially in the setting where the recipient is a child and the intended graft is that of a left lateral segment ${ }^{[8-13]}$. The first laparoscopic donor hepatectomies (left lateral section grafts) were reported in 2002 and were performed for living donor liver transplantation (LDLT) in children ${ }^{[14]}$. A recent large series of 220 consecutive donations in pediatric live donor liver transplants showed similar recipient outcomes including graft survival with better perioperative outcomes of the donors ${ }^{[15]}$. The data on full lobe resection for live donor liver transplant in the adult setting, especially concerning the right lobe, appear to be less clear and are currently being discussed. However, at this time, many centers see encouraging results with this approach ${ }^{[16,17]}$. It is likely that full laparoscopic right lobe hepatectomy, as is the case for the left lateral segments, will become an accepted approach for adult live donor liver transplant as expertise with MILR continues to grow. This approach has become the standard method in some large LDLT centers with exceptionally high volume ${ }^{[18,19]}$.

\section{CURRENT TREATMENT OF PEDIATRIC LIVER TUMORS}

Pediatric liver tumors are uniquely different from adult liver tumors ${ }^{[20]}$. While adult liver tumors typically develop as carcinomas in cirrhotic or otherwise diseased livers, this type of growth is the exception in the pediatric population. Rather, pediatric liver tumors are of embryonic origin and arise in otherwise healthy livers, surrounded by healthy liver parenchyma. As will be explored later on, this understanding has important implications for the resection of liver tumors in children, especially when considering a minimally-invasive approach.

A wide variety of different tumors can arise in the pediatric liver. These include benign tumors such as the infantile hepatic hemangioma as the most common benign liver tumor in children as well as the mesenchymal harmatoma and the focal nodular hyperplasia ${ }^{[1,22]}$. Hepatoblastoma is not only the most common malignant liver tumor in children, but also the most common liver tumor in children in general $^{[21,22]}$. Others, but considerably less common malignant liver tumors in the pediatric populations are the undifferentiated embryonal sarcoma of the liver, the rhabdomyosarcoma of the biliary tree and the hepatocellular carcinoma (HCC) of childhood ${ }^{[21,22]}$. It is of utmost importance that any surgeon treating such tumors is intimately familiar with the details of the clinical development, their growth pattern, their prognosis, as well as the up to date concerted interdisciplinary treatment algorithms of the 
large pediatric tumor study groups. The current treatment approach of pediatric liver tumors is perhaps best exemplified with the treatment algorithm of hepatoblastoma ${ }^{[23,24]}$, the most common pediatric liver tumor $^{[21,22]}$. Hepatoblastoma typically arises before or right around 3 years of age ${ }^{[25,26]}$. Hepatoblastoma shares this important feature with essentially all other pediatric liver tumors, with the exception of HCC of childhood ${ }^{[21,22]}$. While the latter is found mostly in adolescence, the large majority of all other childhood tumors arise at very young age. As it is easily understandable, this insight has significant impact when selecting the operative approach.

Traditionally, knowledge regarding hepatoblastoma has been extracted from the four major cooperative study groups: the International Childhood Liver Tumors Strategy Group (SIOPEL), Children's Oncology Group (COG), the German Society for Pediatric Oncology and Hematology, and the Japanese Study Group for Pediatric Liver Tumors. Because the numbers of patients in these individual groups were low due to the rarity of the disease and all groups used fundamentally different staging and stratification systems, the comparability of the data obtained was limited ${ }^{[23,24]}$. For this reason, with the involvement of the four groups, a worldwide coalition for the study of hepatoblastomas was formed ${ }^{[4,24]}$. As one of its first tasks, CHIC has recently generated a novel risk stratification based on data from more than 1,600 children treated for 25 years for hepatoblastoma. This risk stratification is based on the stage classification according to PRETEXT (pre-treatment extension), the initial AFP value at diagnosis, the presence of metastases, the presence of vascular invasión and the age of the child, and characterizes the four risk levels: very low, low, intermediate and high ${ }^{[24]}$. Because this stratification system will be used in a new global research study on hepatoblastoma (PHITT) starting in 2018, all other risk stratifications regarding hepatoblastoma have become obsolete. In the PHITT trial, the PRETEXT (pre-treatment extension) grouping system of SIOPEL is used for childhood liver tumors ${ }^{[27]}$. This system is based exclusively on pretherapeutic imaging and is thus independent of the surgical or therapeutic intervention. It describes the extent of the tumor across the 4 surgical sectors of the liver and additionally contains defined PRETEXT risk factors. PRETEXT risk factors include invasion of the tumor into one or more hepatic veins (abbreviated by the letter $\mathrm{V}$ ) or portal vein $(\mathrm{P})$ and extrahepatic tumor invasion (E), tumor rupture (R) or multifocality of the tumor $(\mathrm{F})$. Because a high prognostic relevance for this classification has been proven, it has gained international acceptance ${ }^{[24]}$. In the studies of the US COG, until recently, the traditional staging system, which relies on tumor size in terms of resectability, was used at the same time ${ }^{[21,22]}$. Because of its primarily surgical perspective, this system has above all relevance in $\mathrm{HCC}^{[21]}$. However, the COG-staging system is not part of the PHITT trial ${ }^{[24]}$.

Since most childhood liver tumors are either benign and partly regress spontaneously (infantile hepatic hemangioma) or respond well to chemotherapy (hepatoblastoma), primary resection is usually not indicated as a primary therapeutic approach ${ }^{[21,22]}$. This understanding is especially true in infants, toddlers and schoolchildren. Primary resection in benign tumors is indicated when they grow in size, when there are radiological changes suspicious of malignancy and/or if they become symptomatic ${ }^{[22]}$. As part of the PHITT trial, the surgical treatment decision is clearly regulated and represents a separate study branch within the trial. According to the trial, an initial resection is indicated in children only if there is a stage PRETEXT I or II liver tumor and the tumor is safely removable via a simple lobectomy (trial details at https://clinicaltrials. gov/ct2/show/NCT03017326). All other children undergo a biopsy first and then, if the diagnosis of a hepatoblastoma is confirmed, two cycles of chemotherapy are initiated. After reimaging, the resection will be performed as long as it can be carried out as a simple lobectomy and only if the tumor can be removed safely and completely with this approach. If this is not possible, there will be two more chemotherapy blocks, blocks 3 and 4. During the administration of blocks 3 and 4, the child is evaluated for liver transplantation, which can then be carried out without further delay after completion of block 4 . In individual cases, the improvement after the end of block 4 may instead of the liver transplantation call for a complex or extended resection, always on the premise that the tumor can be completely removed. In cases where there is doubt of resectability, the surgery can be performed when an organ becomes available and with another recipient 
ready as a backup in case the tumor can be successfully resected. Reviewing the results of this study section of the PHITT trial will hopefully clarify which patients will benefit more from extended resection $v s$. transplantation and vice versa. For children who undergo resection, the study does not distinguish between an open and a laparoscopic approach. However, it is clear that any innovative surgical technique such as MILR must be properly integrated in a way that respects these surgical parameters.

\section{MINIMALLY-INVASIVE HEPATOBILIARY SURGERY IN THE PEDIATRIC POPULATION}

Minimally-invasive hepatobiliary surgery has long been established in the pediatric population. As is the case for adults, one of the most commonly performed minimally-invasive hepatobiliary surgeries carried out in children is cholecystectomy. This surgery can be safely performed by single-incision laparoscopic surgery $(\text { SILS })^{[28]}$. More complex operations of reconstructive nature are similarly standard of care in pediatric surgery. Resection of a choledochal cyst and reconstruction of bile flow with hepaticojejunostomy is routinely carried out in pediatric surgery, although some centers report higher complication rate compared to open surgery ${ }^{[29,30]}$. This operation has been carried out successfully with a SILS approach ${ }^{[31]}$. One of the major longterm complications of choledochal cyst resection is, independent of the surgical approach, stenosis of the hepaticojejunal anastomosis requiring dilation by the interventional radiologist or surgical revision. Redo hepaticojejunostomy for children with choledochal cyst can - in experienced hands - be carried out safely as a minimally-invasive approach ${ }^{[32,33]}$. Other indication in which laparoscopic hepatobiliary surgery has been advocated in the pediatric population is the resection of hepatic cysts, even in the neonates ${ }^{[34,35]}$. Although these cysts rarely require intervention, if they do they usually do not require formal liver resections but simple cyst resection.

While the above-mentioned indications have withheld the test of time and are widely accepted amongst pediatric surgeons around the world, one indication remains controversial. The excitement for the early success of laparoscopic hepatobiliary surgery in children, especially that of choledochal cyst resection, has lead to the laparoscopic reconstruction of biliary atresia over open reconstruction, which was until then the mainstay therapy of this disease as a bridge to liver transplant. Despite the initial enthusiasm, increasing evidence shows inferior outcomes for the laparoscopic approach of this sophisticated procedure ${ }^{[36-38]}$, which is currently not considered standard of care. Nevertheless, a recent study with a large sample size has shown, for the first time, an equal outcome for the laparoscopic approach when looking at 3 and 5 -year native liver survival, confusing the interpretation of current data ${ }^{[39]}$. At our center, we perform the Kasai procedure open for all cases of biliary atresia unless primary liver transplant is necessary.

Laparoscopic correction of extra-hepatic congenital portosystemic shunts (CPS) in children has also been described ${ }^{[40]}$. CPS is a rare entity and may lead to the development of jaundice, encephalopathy and pulmonary hypertension ${ }^{[41]}$. Obliteration of the shunt by the interventional radiologist by coiling or with a vascular plug is not always an option, especially in large shunts or in those with flow directed to the inferior vena cava with risk of migration of the foreign body into the heart. While the laparoscopic approach could be an option, open laparotomy is generally required in these cases.

\section{MILR FOR PEDIATRIC LIVER TUMORS}

Although laparoscopic hepatobiliary surgery is commonplace in pediatric surgery, anatomical liver resection in the pediatric population remains one of the last ambitions in the evolution of laparoscopic surgery. This understanding is explained partially by the low frequency of liver tumors in children, which makes it difficult for surgeons to accumulate experience with this technique.

Thus far, most laparosocopic hepatectomies reported in children are case reports and small case series of non-anatomical resections for small, peripheral and isolated lesions ${ }^{[34,42-46]}$. Tabrizian and Midulla ${ }^{[34]}$ and 

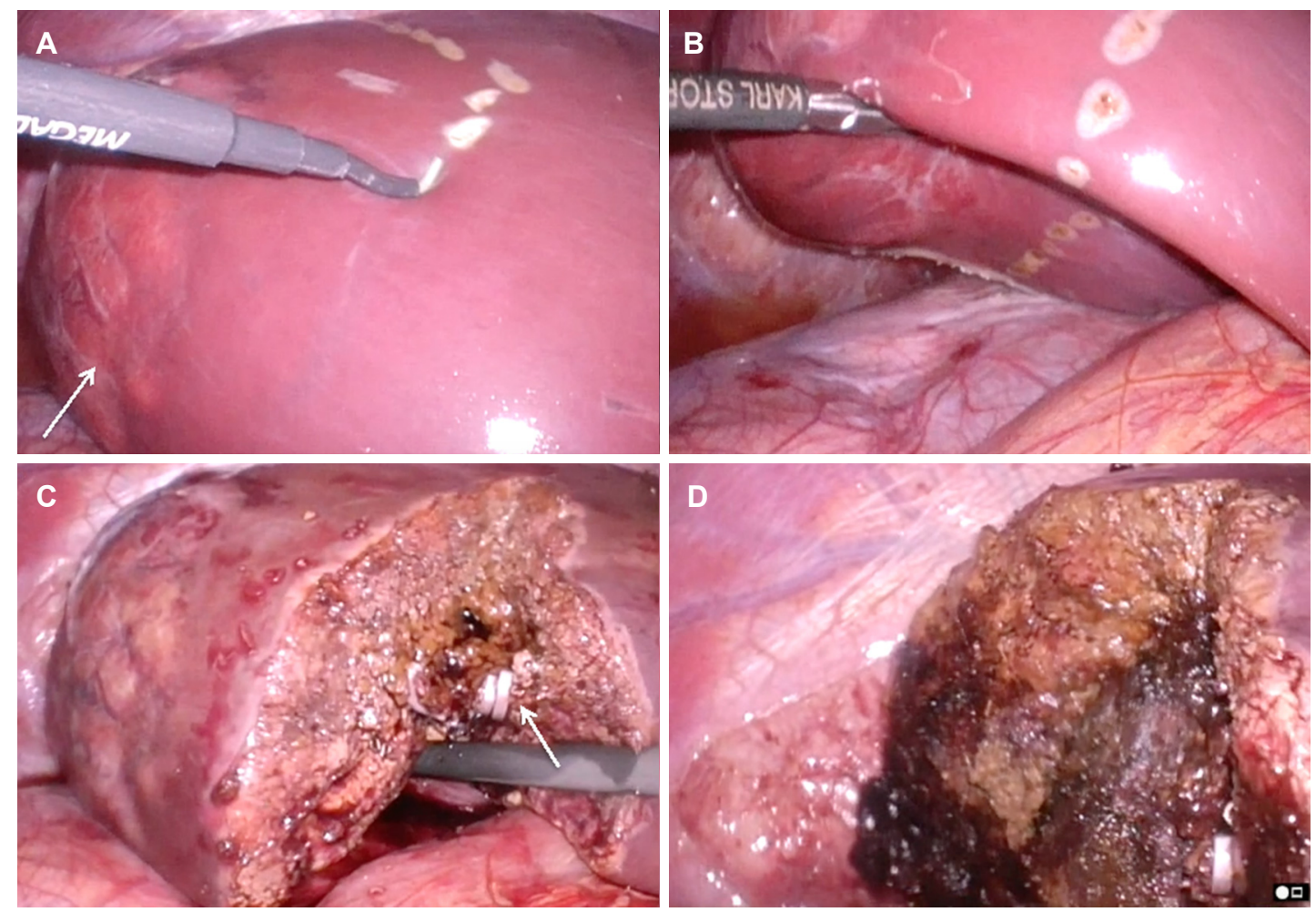

Figure 1. Intraoperative view of an anatomical segment 7 resection of a 12-year-old girl with a large adenoma. A: The resection line is being mapped out with the electrocautery, the tumor in segment 7 is shown (white arrow); B: the mobilized right lobe is shown with the resection line completely mapped out; $\mathrm{C}$ : the corresponding Glisson bundle of segment 7 with its portal vein branch, arterial branch and bile duct is divided between clips (white arrow); D: the completed resection. There was only minimal blood loss in the case

Oh et al ${ }^{[43]}$ used a full laparoscopic approach to excise hepatic cysts. Interesting about these two particular case reports is the fact that both children had large cysts and were rather young, one being a newborn and the other being only 2-month-old. Dutta et al. ${ }^{[42]}$ reported a case of successful non-anatomical laparoscopic hepatic resection of a large mesenchymal hamartoma. This operation took place in a 2-year-old boy. Yoon et al. ${ }^{[4]]}$ performed a total laparoscopic left lateral sectionectomy in a 5-year-old girl who suffered from the same tumor. The operative time in their case was $150 \mathrm{~min}$ and the estimated blood loss was $100 \mathrm{~mL}$. There were no complications and the length of stay (LOS) was 11 days. The postoperative pathology showed a disease-free resection margin and confirmed the diagnosis of mesenchymal hamartoma of the liver. Kim et al ${ }^{[45]}$ in 2011 reported on 38 children with confirmed diagnosis of hepatoblastoma treated between 1991 and 2009 at the Asan Medical Center Children's Hospital in Seoul, Korea ${ }^{[45,46]}$. In their retrospective review, of the 38 children with hepatoblastoma, a total of two resections were carried out as total laparoscopic resections and both cases were partial hepatectomies. There were no complications and both children were free of disease at follow up after 8.1 and 19.3 months, respectively. In Figure 1 we present a case of our own unpublished cohort. This 12-year-old girl suffered from a large hepatic adenoma and underwent laparoscopic resection of segment 7. There were no complications and the tumor was removed with negative margins.

Besides these anecdotal case reports, there is only one larger study on the subject in the current English literature. Michaelle Veenstra and Alan Koffron published in 2015 this first comprehensive review of MILR in children ${ }^{[47]}$. In their retrospective review, they included 36 children who underwent MILR for benign and malignant disease. For these children, the data analyzed included patient demographics, operative technique, pathology, complications, recurrence, and outcome. From a technical point of view, MILR was carried out as one of the following three approaches: pure laparoscopic, hand-assisted laparoscopy, and a hybrid laparoscopic assisted method. In the latter approach, the initial parts of the resection were 
carried out laparoscopically and finished as an open resection, overall allowing for a smaller incision than typically necessary for an open resection. Of all patients on the case series, 19 were females and the mean age was 2.7 years (9 months to 17 years). While three of these patients were adolescents between 12-16 years undergoing liver resection for benign tumors, two were under the age of 2 years undergoing liver resection for hepatoblastoma ${ }^{[47]}$. Of all resections carried out, 15 were for benign tumors and 21 were for malignant tumors. Of the 21 children with malignant tumors, 20 had hepatoblastoma and the remaining one was an adolescent of 17 years with a fibrolamellar HCC. All were unifocal lesions with a size ranging from 2-16 cm in the benign tumor group and from $2-9 \mathrm{~cm}$ in the malignant tumor group. Of the 36 children, 31 (86\%) surgeries were performed as pure laparoscopic resections and 5 (14\%) were carried out either as hand-assisted or hybrid procedures. Of the 31 purely laparoscopically performed resections, 10 were segmentectomies, 5 were sectionectomies, and 16 were hemihepatectomies. Of the 5 hand-assisted or hybrid procedures, one was a segmentectomy, and 4 were hemihepatectomies. The operative time correlated with the amount of liver resected and was 74 (50-110) $\mathrm{min}$ for the segmentectomy group, 120 (48-200) $\mathrm{min}$ for the sectionectomies and 195 (55-450) min for the hemihepatectomies. Five patients required blood transfusion, 4 of which underwent hemihepatectomy as hand-assist or hybrid procedure. Five patients suffered postoperative complications. There was one seroma, one port site infection, one-line infection, one port dehiscence, and one hypertrophic scar. The LOS was 3 days (2-6) for the segmentectomies, 4 days (2-5) for the sectionectomies, and 5 days (2-9) for the hemihepatectomies. This LOS is shorter compared of what is published for open resection of malignant tumors in children ${ }^{[48]}$. All malignant tumors were removed with Ro margins. Follow-up for children with malignant disease was 12-36 months and there were no local recurrences. One child had pulmonary metastasis prior to resection, which had resolved on radioimaging following neoadjuvant chemotherapy, however, this child had recurrence of the pulmonary lesions during the follow-up period after the resection. In this same study, patients not considered for MILR were those that would not tolerate laparoscopy, malignant lesions that could not be safely removed with adequate margins laparoscopically and those with lesions too close to major vascular or biliary structures on imaging to allow safe laparoscopic resection $^{[47]}$. Taken together, although their review does not include comparisons to contemporaneous open controls, this comprehensive report for the first time shows that with appropriate patient selection and the necessary expertise, MILR can safely be carried out in children with both benign and malignant liver disease with excellent outcomes and minimal morbidity. Additionally, it clarifies that patients bearing malignant tumors with PRETEXT III or above (three sections are involved, and no two adjoining sections are free), with macrovascular invasion that require reconstruction of the vena cava or the portal vein, or with doubts of resectability in whom liver transplantation is the next treatment option, may be poor candidates for MILR.

\section{OUTLOOK INTO THE FUTURE}

Minimally-invasive hepatobiliary surgery in children requires not only specialized equipment but also particular expertise in order to confine precision work in the enclosed space of the child's abdominal cavity. This is especially important for the consideration of MILR for pediatric tumors, because they typically arise before the age of 3 years, when the entire abdominal cavity has the average size of an adult man's liver. Therefore, a hand-assisted approach, which is wide spread in adult MILR, is more difficult to perform in the child due to the enclosed working space. Also, the incision required for the hand-port nearly confines the incision necessary for open surgery, especially in a small child, therefore reducing the effect of "minimallyinvasive" surgery. However, it is important to note that the incision for a hand-port is usually vertical in the midline of the upper abdomen and does not transect the rectus muscle, usually the main driver of postoperative pain following typical open surgery. Nevertheless, unless operating on a large child or an adolescent, hand-assisted MILR is unlikely to represent a breakthrough in pediatric oncological liver surgery. On the contrary, other techniques widely spread in the pediatric population may be of great benefit when considering MILR in this particular population. Perhaps its biggest value can be found in cases that are elaborate and may otherwise not be completed safely without full conversion. Foremost, this includes SILS. 
SILS allows operating through one access site, eliminating the multiple sites traditionally used, even in small children ${ }^{[28]}$. When performing complex hepatobiliary cases laparoscopically in a child, including MILR, we advocate using a hybrid approach in which the SILS-port is used in addition to traditional trocar sites. This allows introducing more instruments from various angles without making additional incisions and hence gives more flexibility for the intracorporal work. In such an approach, the incision for the SILS-port can safely be extended up to $5 \mathrm{~cm}$ or more depending on the type of port used, an ideal length for either extraction of bowel for an extracorporal anastomosis or for the extraction of a resected tumor. Importantly, different from traditional laparoscopically-assisted procedures, the SILS-port, after having been taken out the tumor specimen, will remain a seal and can be reinserted unlimited amount of times despite the extension of the original incision. This allows for greater flexibility when performing combined intra- and extracorporeal reconstructive work or when removing more than one tumor specimen at a time. Although complete hepatectomy has been successfully carried out in adults uniquely through SILS ${ }^{[4]}$, the authors have no experience nor know of any experience with performing MILR in children exclusively through a SILS port other than for simple atypical resections of peripheral lesions. However, the enclosed space of the pediatric abdominal cavity in children put aside, theoretically there is no reason that such a procedure is technically not feasible. One wonders though, given the small size of additional trocar sites in children, if it is necessary.

Robotic surgery has been recently introduced in the clinical practice and it has been accepted as an effective option to perform high-demanding procedures including hepatobiliary surgery in adults ${ }^{[50]}$. A recent review on the application of robotic surgery to liver surgery in adults when compared to open or laparoscopic shows no inferiority, however, randomized control trials are necessary to reach broader conclusions ${ }^{[51]}$. The role of robotic surgery in pediatric surgery remains controversial partly because of the lack of pediatric-sized robotic instruments and equipment, the elevated cost and the need for robotic-trained pediatric surgeons. In children, similar to adult surgery, robotic surgery has become popular in pediatric urology, being the pyeloplasty and partial nephrectomies the more accepted procedures ${ }^{\left[5_{2}\right]}$. Nothing is known about the role and the advantages of robotic procedures in liver surgery in children.

Independent of the technical challenges in MILR in children, the most important task of our field will be to assure that the current recommendations for surgical resection of the corresponding pediatric oncological study groups, especially CHIC, are not compromised by the innovation of MILR. This is especially true for malignant tumors such as hepatoblastoma and HCC, for which there is overwhelming evidence that incomplete resection significantly worsens prognosis, even if followed by liver transplant ${ }^{[23]}$. As MILR continues to grow within pediatric oncology, more research is needed to evaluate the full impact of MILR in children. The current evidence is summarized in Table 1, representing one article with level III evidence (comprehensive retrospective review) and several articles with level IV evidence (case reports and case series). A large prospective study would be the highest possible level of evidence addressing the question of whether there are significant differences in outcome and morbidity between open and laparoscopic liver resection for pediatric tumors and would certainly be much desired. However, similar to the obstacles found when creating the current PHITT study, due to the rarity of hepatic tumors in children, such a trial would have to be designed as a global effort in order to obtain adequate numbers for reliable statistical analysis. Until then, it would be nevertheless of immense value if more literature were to become available on the subject, whether small prospective studies or comprehensive retrospective reviews.

\section{CONCLUSION}

MILR for liver tumors is the last bastion in the evolution of pediatric hepatobiliary surgery. Slowly, accumulating evidence around the world indicates that with experience and careful patient selection, laparoscopic liver resections can be carried out safely and without compromising outcomes. The children operated with this approach appear to benefit from the typical advantages of minimally-invasive surgery. 
Table 1. Overview of existing literature for minimally-invasive liver resection in children

\begin{tabular}{|c|c|c|c|c|c|c|c|}
\hline Year & Ref. & Article type & Study population & Age & $n$ & Type of resection & $\begin{array}{l}\text { Level of } \\
\text { evidence }\end{array}$ \\
\hline 2006 & Yoon et al. ${ }^{[44]}$ & Case report & Mesenchymal hamartoma & 5 years & 1 & $\begin{array}{l}\text { Total laparoscopic left lateral } \\
\text { sectionectomy }\end{array}$ & 4 \\
\hline 2007 & Dutta et $a l^{[42]}$ & Case report & Mesenchymal hamartoma & 2 years & 1 & Successful non-anatomical resection & 4 \\
\hline 2010 & $\begin{array}{l}\text { Tabrizian and } \\
\text { Midulla }^{[34]}\end{array}$ & Case report & Congential hepatic cyst & 2 months & 1 & Complete laparoscopic cyst excision & 4 \\
\hline 2011 & Kimet al. ${ }^{[45]}$ & Case series & Hepatoblastoma & $\begin{array}{l}9 \text { months, } \\
2 \text { years }\end{array}$ & 2 & $\begin{array}{l}\text { Totally laparoscopic partial } \\
\text { hepatectomy }\end{array}$ & 4 \\
\hline 2012 & Ohet al. ${ }^{[43]}$ & Case report & Congential hepatic cyst & $\begin{array}{l}6 \text { weeks } \\
\text { premature }\end{array}$ & 1 & Complete laparoscopic cyst excision & 4 \\
\hline 2016 & Linden et $a / .^{[35]}$ & Case series & Congential hepatic cyst & $\begin{array}{l}5 \text { days, } 7 \text { weeks, } \\
6 \text { years, } \\
14 \text { years }\end{array}$ & 4 & Complete laparoscopic cyst excision & 4 \\
\hline 2016 & $\begin{array}{l}\text { Veenstra and } \\
\text { Koffron }^{[47]}\end{array}$ & $\begin{array}{l}\text { Restrospective } \\
\text { review }\end{array}$ & $\begin{array}{l}\text { Benign and malignant liver } \\
\text { tumors }\end{array}$ & $\begin{array}{l}9 \text { months to } \\
17 \text { years }\end{array}$ & 36 & $\begin{array}{l}\text { Segmentectomy, sectionectomy, or } \\
\text { hemihepatectomy }\end{array}$ & 3 \\
\hline
\end{tabular}

Nevertheless, evidence regarding the topic remains scarce and of poor quality, and further efforts must take place to evaluate the full impact of MILR in children. Most importantly, applying this surgical innovation should not compromise prognosis of children with hepatic tumors.

\section{DECLARATIONS}

Acknowledgement

We thank Khrisna Menon, MD, Liver Transplantation, Institute of Liver Studies, Liver Transplant Surgery, King's College Hospital, National Health Service Foundation Trust, London, United Kingdom for revising the manuscript and for providing the graphical illustration shown in this article.

\section{Authors' contributions}

Literature search, analyse and wrote the manuscript: Cortes-Cerisuelo M, Berger M

\section{Availability of data and materials}

Not applicable.

\section{Financial support and sponsorship}

None.

\section{Conflicts of interest}

All authors declared that there are no conflicts of interest.

\section{Ethical approval and consent to participate}

Not applicable.

\section{Consent for publication}

Not applicable.

\section{Copyright}

(c) The Author(s) 2019.

\section{REFERENCES}

1. Wakabayashi G, Cherqui D, Geller DA, Buell JF, Kaneko H, et al. Recommendations for laparoscopic liver resection: a report from the second international consensus conference held in Morioka. Ann Surg 2015;261:619-29.

2. Koffron AJ, Auffenberg G, Kung R, Abecassis M. Evaluation of 300 minimally invasive liver resections at a single institution: less is more. Ann Surg 2007;246:385-92; discussion 392-4. 
3. Koffron A, Geller D, Gamblin TC, Abecassis M. Laparoscopic liver surgery: shifting the management of liver tumors. Hepatology 2006;44:1694-700.

4. Czauderna P, Haeberle B, Hiyama E, Rangaswami A, Krailo M, et al. The Children's Hepatic tumors International Collaboration (CHIC): novel global rare tumor database yields new prognostic factors in hepatoblastoma and becomes a research model. Eur J Cancer 2016;52:92-101.

5. Han HS, Cho JY, Yoon YS. Techniques for performing laparoscopic liver resection in various hepatic locations. J Hepatobiliary Pancreat Surg 2009;16:427-32.

6. Guro H, Cho JY, Han HS, Yoon YS, Choi Y, et al. Current status of laparoscopic liver resection for hepatocellular carcinoma. Clin Mol Hepatol 2016;22:212-8.

7. Han HS, Shehta A, Ahn S, Yoon YS, Cho JY, et al. Laparoscopic versus open liver resection for hepatocellular carcinoma: case-matched study with propensity score matching. J Hepatol 2015;63:643-50.

8. Thenappan A, Jha RC, Fishbein T, Matsumoto C, Melancon JK, et al. Liver allograft outcomes after laparoscopic-assisted and minimal access live donor hepatectomy for transplantation. Am J Surg 2011;201:450-5.

9. Troisi R, Debruyne R, Rogiers X. Laparoscopic living donor hepatectomy for pediatric liver transplantation. Acta Chir Belg 2009;109:559-62.

10. Troisi RI, Wojcicki M, Tomassini F, Houtmeyers P, Vanlander A, et al. Pure laparoscopic full-left living donor hepatectomy for calculated small-for-size LDLT in adults: proof of concept. Am J Transplant 2013;13:2472-8.

11. SSoubrane O, de Rougemont O, Kim KH, Samstein B, Mamode N, et al. Laparoscopic living donor left lateral sectionectomy: a new standard practice for donor hepatectomy. Ann Surg 2015;262:757-61; discussion 761-3.

12. Chen KH, Siow TF, Chio UC, Wu JM, Jeng KS. Laparoscopic donor hepatectomy. Asian J Endosc Surg 2018;11:112-7.

13. Han YS, Ha H, Kwon HJ, Chun JM. Pure laparoscopic donor right hepatectomy in a living donor with type 3a biliary variation: a case report. Medicine (Baltimore) 2017;96:e8076.

14. Cherqui D, Soubrane O, Husson E, Barshasz E, Vignaux O, et al. Laparoscopic living donor hepatectomy for liver transplantation in children. Lancet 2002;359:392-6.

15. Broering DC, Elsheikh Y, Shagrani M, Abaalkhail F, Troisi RI. Pure laparoscopic living donor left lateral sectionectomy in pediatric transplantation: a propensity score analysis on 220 consecutive cases. Liver Transpl 2018;24:1019-30.

16. Kim KH, Kang SH, Jung DH, Yoon YI, Kim WJ, et al. Initial outcomes of pure laparoscopic living donor right hepatectomy in an experienced adult living donor liver transplant center. Transplantation 2017;101:1106-10.

17. Lee KW, Hong SK, Suh KS, Kim HS, Ahn SW, et al. One hundred and fifteen cases of pure laparoscopic living donor right hepatectomy at a single center. Transplantation 2018;102:1878-84.

18. Han HS, Cho JY, Kaneko H, Wakabayashi G, Okajima H, et al. Expert panel statement on laparoscopic living donor hepatectomy. Dig Surg 2018;35:284-8.

19. Chen KH, Huang CC, Siow TF, Chio UC, Chen SD, et al. Totally laparoscopic living donor right hepatectomy in a donor with trifurcation of bile duct. Asian J Surg 2016;39:51-5.

20. von Schweinitz D. Hepatoblastoma: recent developments in research and treatment. Semin Pediatr Surg 2012;21:21-30.

21. Zimmermann A, Perilongo G. Pediatric liver tumors. Available from: https://link.springer.com/book/10.1007/978-3-642-14504-9\#toc. [Last accessed on 18 Dec 2018]

22. Holcomb GW, Murphy JD, Ostlie DJ. Ashcraft's Pediatric Surgery. 6th ed. Elsevier; 2014.

23. Meyers RL, Czauderna P, Otte JB. Surgical treatment of hepatoblastoma. Pediatr Blood Cancer 2012;59:800-8.

24. Meyers RL, Maibach R, Hiyama E, Häberle B, Krailo M, et al. Risk-stratified staging in paediatric hepatoblastoma: a unified analysis from the Children's Hepatic tumors International Collaboration. Lancet Oncol 2017;18:122-31.

25. Ross JA, Gurney JG. Hepatoblastoma incidence in the United States from 1973 to 1992. Med Pediatr Oncol 1998;30:141-2.

26. Ross JA. Hepatoblastoma and birth weight: too little, too big, or just right? J Pediatr 1997;130:516-7.

27. Roebuck DJ, Aronson D, Clapuyt P, Czauderna P, de Ville de Goyet J, et al. 2005 PRETEXT: a revised staging system for primary malignant liver tumours of childhood developed by the SIOPEL group. Pediatr Radiol 2007;37:123-32.

28. Seims AD, Nice TR, Mortellaro VE, Lacher M, Ba'Ath ME, et al. Routine utilization of single-incision pediatric endosurgery (SIPES): a 5-year institutional experience. J Laparoendosc Adv Surg Tech A 2015;25:252-5.

29. Nederlandse Studiegroep voor Choledochus Cysten/malformaties (NeSCHoC), van den Eijnden MHA, de Kleine RHJ, de Blaauw I, Peeters PGJM, et al. Choledochal malformation in children: lessons learned from a Dutch National study. World J Surg 2017;41:2631-7.

30. Lee H, Hirose S, Bratton B, Farmer D. Initial experience with complex laparoscopic biliary surgery in children: biliary atresia and choledochal cyst. J Pediatr Surg 2004;39:804-7; discussion 804-7.

31. Son TN, Liem NT, Hoan VX. Transumbilical laparoendoscopic single-site surgery with conventional instruments for choledochal cyst in children: early results of 86 cases. J Laparoendosc Adv Surg Tech A 2014;24:907-10.

32. Diao M, Li L, Cheng W. Laparoscopic redo hepaticojejunostomy for children with choledochal cysts. Surg Endosc 2016;30:5513-9.

33. Diao M, Li L, Cheng W. Recurrence of biliary tract obstructions after primary laparoscopic hepaticojejunostomy in children with choledochal cysts. Surg Endosc 2016;30:3910-5.

34. Tabrizian P, Midulla PS. Laparoscopic excision of a large hepatic cyst. JSLS 2010;14:272-4.

35. Linden AF, Pulcrano ME, Duffy BJ, Lange PA, Tsung DY, et al. Laparoscopic excision of congenital hepatic cysts in the pediatric population: a case series and literature review. J Laparoendosc Adv Surg Tech A 2016;26:493-7.

36. Wong KK, Chung PH, Chan KL, Fan ST, Tam PK. Should open Kasai portoenterostomy be performed for biliary atresia in the era of laparoscopy? Pediatr Surg Int 2008;24:931-3.

37. Chan KW, Lee KH, Tsui SY, Wong YS, Pang KY, et al. Laparoscopic versus open Kasai portoenterostomy in infant with biliary atresia: a retrospective review on the 5-year native liver survival. Pediatr Surg Int 2012;28:1109-13.

38. Lishuang M, Zhen C, Guoliang Q, Zhen Z, Chen W, et al. Laparoscopic portoenterostomy versus open portoenterostomy for the 
treatment of biliary atresia: a systematic review and meta-analysis of comparative studies. Pediatr Surg Int 2015;31:261-9.

39. Li Y, Xiang B, Wu Y, Wang C, Wang Q, et al. Medium-term outcome of laparoscopic Kasai portoenterostomy for biliary atresia with 49 cases. J Pediatr Gastroenterol Nutr 2018;66:857-60.

40. Kimura T, Soh H, Hasegawa T, Sasaki T, Kuroda S, et al. Laparoscopic correction of congenital portosystemic shunt in children. Surg Laparosc Endosc Percutan Tech 2004;14:285-8.

41. Watanabe A. Portal-systemic encephalopathy in non-cirrhotic patients: classification of clinical types, diagnosis and treatment. J Gastroenterol Hepatol 2000;15:969-79.

42. Dutta S, Nehra D, Woo R, Cohen I. Laparoscopic resection of a benign liver tumor in a child. J Pediatr Surg 2007;42:1141-5.

43. Oh PS, Hirose S, Parakh S, Cowles RA. Laparoscopic excision of an antenatally diagnosed large simple hepatic cyst in the newborn. Pediatr Surg Int 2012;28:719-23.

44. Yoon YS, Han HS, Choi YS, Lee SI, Jang JY, et al. Total laparoscopic left lateral sectionectomy performed in a child with benign liver mass. J Pediatr Surg 2006;41:e25-8.

45. Kim T, Kim DY, Cho MJ, Kim SC, Seo JJ, et al. Surgery for hepatoblastoma: from laparoscopic resection to liver transplantation. Hepatogastroenterology 2011;58:896-9.

46. Kim T, Kim DY, Cho MJ, Kim SC, Seo JJ, et al. Use of laparoscopic surgical resection for pediatric malignant solid tumors: a case series. Surg Endosc 2011;25:1484-8.

47. Veenstra MA, Koffron AJ. Minimally-invasive liver resection in pediatric patients: initial experience and outcomes. HPB (Oxford) 2016;18:518-22.

48. Zwintscher NP, Azarow KS, Horton JD. Morbidity and mortality associated with liver resections for primary malignancies in children. Pediatr Surg Int 2014;30:493-7.

49. Struecker B, Haber P, Öllinger R, Bahra M, Pascher A, et al. Comparison of single-port versus standard multiport left lateral liver sectionectomy. Surg Innov 2018;25:136-41.

50. Araujo RLC, de Castro LA, Fellipe FEC, Burgardt D, Wohnrath DR. Robotic left lateral sectionectomy as stepwise approach for cirrhotic liver. J Robot Surg 2018;12:549-52.

51. Guerra F, Di Marino M, Coratti A. Robotic surgery of the liver and biliary tract. J Laparoendosc Adv Surg Tech A 2018; doi: 10.1089/ lap.2017.0628.

52. Howe A, Kozel Z, Palmer L. Robotic surgery in pediatric urology. Asian J Urol 2017;4:55-67. 